\title{
UMA CONTRIBUIÇÃO PARA A PESQUISA E O DEBATE SOBRE A FORMACุÃO (TRANS) TERRITORIAL DA IBERIA
}

\section{Denise Aparecida Soares de Moura*}

Universidade Estadual Paulista Júlio de Mesquita Filho

Franca - São Paulo - Brasil

Resenha do livro: HERZOG, Tamar. Frontiers of possession: Spain and Portugal in Europe and the Americas. Cambridge: Harvard University Press, 2015. 384 p.

Este é um livro sobre a formação territorial de Portugal e Espanha na época moderna em dois continentes: na Europa e na América. A autora, Tamar Herzog, professora na Universidade Harvard e especialista em temas da história administrativa e da formação das identidades na América hispânica, com ênfase na história do vice-reinado do Peru, abordou este que é um dos temas, desde longa data, focalizado por grandes nomes da historiografia

\footnotetext{
* Doutora em História Econômica pela Faculdade de Filosofia, Letras e Ciências Humanas da Universidade de São Paulo e professora assistente doutor no Departamento de História e no Programa de Pós-Graduação da Faculdade de Ciências Sociais e Humanas da UNESP. Email: denise.moura@franca.unesp.br
} 
luso-brasileira, ${ }^{1}$ do ponto de vista dos múltiplos agentes sociais que viviam nos territórios de fronteira e que estiveram mais diretamente envolvidos com questões de posse e uso da terra.

Para Herzog a história da formação territorial ibérica não pode ser reduzida ao protagonismo do Estado, dos tratados negociados nas mesas diplomáticas internacionais, aos combates no front ou à constituição dos estados nacionais. Ao longo do foco narrativo e analítico de seu livro, o ambiente da fronteira aparece na condição de tribuna democrática, na qual fazendeiros, criadores, nobres, clero, párocos, missionários, povoadores, governadores, autoridades municipais e militares expressaram suas noções de direitos fundiários, recorrendo ao argumento dos direitos de uso antigo e costumeiro. Estes sujeitos sociais, ao longo do tempo, fizeram e desfizeram alianças para defender estes direitos que muitas vezes prescindiram da sua condição de vassalo a uma ou outra coroa, pois o que importava era o direito de posse da terra que, muitas vezes, se estendia para o território vizinho.

Para alcançar este mosaico social e inventariar diversos argumentos defensivos de direitos a autora pesquisou em volumosa e variada documentação, desde relatos de exploradores e missionários, correspondência político-administrativa e papéis judiciais existentes em arquivos de Portugal e Espanha e nos atuais países do Brasil, Argentina, Uruguai e Chile, que foram domínios territoriais destas monarquias no ultramar. A especialização da autora na história político-administrativa do vice-reinado do Peru, com foco na região de Quito, certamente influenciou a concentração de suas pesquisas de campo na região da Amazônia e Paraguai para a elaboração deste livro.

Contrastando e inter-relacionando o problema da formação territorial ibérica na Europa e na América, a autora verificou que, embora em ambos os continentes os agentes sociais tenham tido papel proativo, houve diferenças nos argumentos empregados para a defesa de direitos de uso da terra. Assim, na América, os monarcas de ambas as coroas, embora não possam ser vistos como força predominante das definições territoriais, se envolveram mais com esta questão tanto em virtude da vastidão dos territórios sobre os quais teriam de confirmar sua soberania como devido a necessidade de promo-

\footnotetext{
1 Exemplos de obras clássicas que se envolveram com este tema de maneira ensaística ou aprofundada em sólida pesquisa empírica: ABREU, Capistrano. Caminhos antigos e o povoamento do Brasil. In: Idem. Caminhos antigos e povoamento do Brasil. Rio de Janeiro: Civilização Brasileira, 1975; HOLANDA, Sérgio Buarque de. Monções. $3^{a}$ edição. São Paulo: Ed. Brasiliense, 1990; CORTESÃO, Jaime. Alexandre de Gusmão e o Tratado de Madri. São Paulo: Funag, 2006.2 vol.
} 
verem a incorporação de populações nativas. Como resultado, a definição das fronteiras na Europa foi menos tensa e pouco evocativa da condição de súdito português ou espanhol (p. 245).

Questões como estas estão distribuídas ao longo de uma obra dividida em duas partes contendo dois capítulos cada uma. O foco narrativo do livro é caracterizado por dois componentes que trazem preocupações teóricas com a própria escrita da história ibérica. Ou seja, a autora inverteu o paradigma narrativo Europa-América, começando a discussão do problema a partir desta última. Ao mesmo tempo, preocupou-se em romper com o modelo da divisão da história ibérica entre Portugal e Espanha, optando por tratar os dois espaços em conjunto.

No primeiro caso, seu objetivo foi o de mostrar que a "América não apenas precede a Europa, mas também introduz muitas das questões" que se tornaram objeto de sua investigação (p. 12). O efeito desta inversão em suas conclusões foi o de que as tensões e os debates dos vários agentes sociais sobre a formação territorial no Novo Mundo tiveram ressonância no Velho Mundo. A preocupação excessiva em defender este argumento levou a autora a descrever minuciosamente situações individuais de conflitos de terra em municípios de fronteira na península Ibérica, o que tornou o foco narrativo da segunda parte repetitivo. Um número menor de situações relatadas teria sido convincente, tendo em vista o volume da documentação que a fundamenta.

No segundo caso, ao tratar da história de Portugal e Espanha de maneira articulada e simultânea, a autora explicita um posicionamento teórico que está por trás dos trabalhos contemporâneos em história ibérica e que vem, desconstruindo suas fronteiras. Adeptos desta metodologia e abordagem têm recuperado a narrativa da Hispania, que persistiu para além da dissolução da União Ibérica e previa uma relação de interesses comuns entre os reinos da península Ibérica. Ainda no século XIX e sempre combatida pelos discursos nacionais, esta perspectiva de pensamento persistiu através do movimento denominado Iberismo e que pretendia a fusão de Portugal e Espanha em todos os seus aspectos.

Na primeira parte da obra, a histórica disputa entre as coroas de Portugal e Espanha pelo controle das terras da América, que remonta à assinatura do Tratado de Tordesilhas (1494), é apresentada criticamente a partir de dois planos: o do conflito das interpretações hispânicas e portuguesas das bulas, tratados e doutrinas e o das relações que estabeleceram com as populações indígenas.

Como observou a autora, as limitações de conhecimento geográfico no período, derivadas do próprio nível científico e técnico da época, contribuí- 
ram para dar vazão a muitas e variadas interpretações das determinações dos tratados e para a produção de muitos relatos, bem como debates que opuseram geógrafos e práticos do território (sertanistas) em relação ao correto curso de rios e a localização de sinais topográficos, como montanhas, e que poderiam definir os legítimos direitos fundiários de cada uma das coroas.

Entre seus súditos residentes nas zonas fronteiriças surgiram vários argumentos que poderiam endossar a defesa dos direitos de posse do território, como o do trabalho na terra, que para alguns deveria ser permanente e para outros poderia ser sazonal, como pescar, caçar, criar gado e coletar madeira; a navegação de rios, o comércio com populações nativas ou a abertura de estradas. Na medida em que estes usos e mobilidade fluvial ou terrestre inflamavam os debates, ambas as coroas se mantiveram alertas quanto à movimentação de comerciantes, sertanistas e padres missionários nas áreas em disputa, o que deu origem a um dos agentes sociais mais intrigantes e difíceis de biografar, ou seja, os espiões, que poderiam ser soldados ou sertanistas provenientes da capitania de São Vicente.

Nos arquivos e bibliotecas, a autora reuniu consistente volume de papéis públicos, na forma de correspondências trocadas entre autoridades e relatos de expedições que procuravam demonstrar a precedência na ocupação e, portanto, os direitos de posse territorial defendidos por ambas as coroas.

No segundo capítulo desta primeira parte, é discutida a relação entre conversão, vassalagem e direitos territoriais, através do trabalho intelectual e evangelizador dos missionários portugueses e espanhóis de várias ordens religiosas, cujo resultado garantiu a ambas as coroas argumentos que sustentaram suas reivindicações de direitos territoriais. Alguns desses missionários, como o nativo da Boêmia Samuel Fritz, se tornaram ícones na defesa de direitos territoriais dos espanhóis ou de denúncia das usurpações territoriais portuguesas entre seus contemporâneos e foram tidos como grandes geógrafos e reconhecedores de territórios.

O processo de formação territorial ibérica na América, portanto, contou com a efetiva atuação desses missionários que se estabeleceram justamente na região supostamente atravessada pelo meridiano de Tordesilhas, como a da Amazônia e das províncias do Paraguai. Segundo a autora, as coroas de Portugal e Espanha contavam com o poder dos missionários de persuadir os índios não somente a mudarem suas crenças religiosas, mas também a seguirem religiosos de naturalidade hispânica ou portuguesa, pois isto lhes asseguraria direitos de posse sobre territórios (p. 73).

Esta constatação estende a atuação dos missionários do campo da evangelização para o da formação territorial. Assim, suas rivalidades com outros 
agentes sociais na colônia não se restringiram à sua posição contrária à escravização indígena, como mostraram clássicos da historiografia. ${ }^{2}$ Várias autoridades régias, como governadores, encarregados de defender a soberania de suas coroas na América, vigiaram os movimentos dos missionários nas áreas de fronteira, classificando-os como ameaçadores da ordem vigente e, com isto, reunindo argumentos para combatê-los.

A conversão era útil para o Estado porque resultava em terras e vassalos, mas introduzia também outro problema: o do direito dos nativos a terra, um dos temas que parece ter aquecido os debates dos séculos XVII e XVIII. Com a emergência de novas diretrizes jurídicas no campo das relações internacionais, baseadas no princípio do direito natural, o conceito de soberania política sobre territórios passou a ser mediado pelo de ocupação, o que derrubou a antiga tradição de legítimo poder concessionário do papado.

Assim, as discussões sobre direitos a terra passaram a girar em torno da definição do tipo apropriado de sua ocupação e, por este viés, ambas as coroas conseguiram deslegitimar os direitos de posse dos índios convertidos. As distâncias de terras desocupadas que deveriam existir entre um grupo indígena e outro, por exemplo, consideradas espaços para caça ou para extração de seus recursos foram consideradas terras vacantes e sujeitas à ocupação pela Coroa, por exemplo. Deste modo, a ordem régia encontrou uma solução para conciliar conversão com concentração de terras, o que no longo prazo influenciou a estrutura fundiária desigual e conflituosa da América ainda nos dias de hoje.

Da formação ibérica na América a autora deslocou o seu foco, na segunda parte da obra, para o espaço da península Ibérica e nesta identificou uma série de similaridades, do ponto de vista da multiplicidade de agentes sociais e a defesa de direitos de posse territorial segundo argumentos específicos. Embora Portugal e Castela negociassem suas fronteiras desde a Idade Média, municipalidades, igrejas, contrabandistas e gente que se denominava fronteira - que vivia e se definia deste ponto de vista geográfico - questionavam divisas e negavam que sua identidade deveria coincidir com divisões político-administrativas oficiais.

Ponto alto desta parte são as constatações da autora sobre as diferenças no processo de formação territorial ibérica na América e na península. Na América, território do Novo Mundo, os conflitos por terra eram mais recen-

\footnotetext{
2 MONTEIRO, John. Negros da terra: índios e bandeirantes nas origens de São Paulo. São Paulo: Companhia das Letras, 1995.
} 
tes, contavam com alianças interétnicas que se faziam e desfaziam circunstancialmente e os europeus tiveram pela frente a tarefa de apagar a história do continente, o que significou construir imagens e argumentos que suprimissem os direitos de posse dos antigos habitantes do território.

Esta última questão pode ter tido algum tipo de similaridade com o contexto das guerras de reconquista, quando os ibéricos expulsaram os mulçumanos da península. Em ambos os continentes, houve um processo de detração dos habitantes das fronteiras - fronterizos. Com esta discussão a autora cumpre sua promessa metodológica apresentada na introdução, fazendo com que as formações territoriais ibéricas nas duas pontas do Atlântico enriqueçam-se mutuamente.

Ainda nesta parte, a imagem da hidra, personagem da mitologia grega com várias cabeças, as quais sendo cortadas voltavam a nascer, serviu para indicar quão complexos foram estes conflitos, mesmo quando as divisões entre os dois reinos foram definidas. Municípios como Aroche e Encinasola (Castela) ou Serpa e Moura (Portugal), por exemplo, revezaram entre alianças e conflitos em relação à garantia de uso de suas terras, importando menos a que coroa deviam jurar vassalidade.

No bojo dos conflitos entre estas municipalidades, a autora inova ao demonstrar que as preocupações com as divisões das linhas de fronteira eram mais oriundas das populações locais do que das coroas. As fronteiras não foram, portanto, invenção dos estados ou dos monarcas, mas das populações que desejavam definir onde seu gado podia pastar, onde podiam plantar ou coletar madeiras (p. 184).

Este é um livro, portanto, cujas diretrizes teórico-metodologicas estão afinadas com uma das mais recentes abordagens da história ibérica crítica dos esquemas analíticos nacionais e que podem ser encontradas em trabalhos individuais, de grupos de discussão ${ }^{3}$ e em iniciativas de acadêmicos que

\footnotetext{
3 Destaco o grupo de discussão que se reúne anualmente no The College William \& Mary, coordenado por Fabrício Prado e que tem dado tratamento trans-imperial à história do rio da Prata em especial. Destaco ainda trabalhos como: PRADO, Fabrício. In the shadows of empires: trans-imperial networks and colonial identity in Bourboun rio de la Plata (c. 1750-c. 1813). Dissertação em História colonial, História da America Latina, Emory University, 2009; PIMENTA, João Paulo. A independência do Brasil e a experiência hispano americana (1808-1822). São Paulo: Hucitec, 2015; MOURA, Denise A. Soares de. An expanding mercantile circuit in the South Atlantic in the late colonial period (1796-1821). E-Journal Portuguese History, vol. 13, n. 1. Brown: Brown University, 2015, p. 68-88. Disponível em: https://www.brown.edu/Departments/Portuguese_Brazilian_Studies/ ejph/html/issue25/pdf/v13n1a03.pdfhttps://www.brown.edu/Departments/Portuguese_Brazilian_Studies/ejph/html/issue25/pdf/v13n1a03.pdf. Acesso em: 17/08/2016.
} 
optam pelo agregamento em rede. Herzog, no caso, é uma das coordenadoras da Red Columnaria. ${ }^{4}$

Mesmo diante deste volume de adeptos da ideia do tratamento articulado entre as histórias de Portugal e Espanha a autora considera que poucos ainda parecem dispostos a adotar o conceito de Ibéria como unidade de análise (p. 250) fora do convencional intervalo cronológico da União Ibérica (1580-1640).

Na tradição dos estudos latino-americanos nos Estados Unidos este trabalho de Herzog continua com perspectivas já apresentadas por certo autor na década de 1970, em tese ainda inédita e que discutiu a formação territorial da região do Madeira-Mamoré e Amazonas através também da atuação de párocos, índios, sertanistas e jesuítas, enfatizando a importância de uma questão como esta ser focalizada para além do mundo de diplomatas, conselheiros do rei e autoridades régias. ${ }^{5}$

Embora densamente fundamentado em evidências empíricas e bibliografia pertinente ao tema central da pesquisa, o livro é deficitário em relação à historiografia brasileira recente, o que chama atenção porque a proposta da autora é trabalhar a formação territorial também de Portugal na América. Um déficit como este poderia ter sido evitado com o rastreamento de artigos publicados pelas principais revistas acadêmicas em História do Brasil, do mesmo modo como a autora fez exaustivamente nas revistas em língua hispânica e inglesa.

De modo geral, a formação territorial é pensada a partir das áreas de fronteira. Mas, nos ambientes urbanos e das fronteiras internas (os sertões), observa-se um fenômeno bastante semelhante ao verificado por Herzog, ou seja, as articulações e rearticulações dos diferentes agentes sociais, independentes de hierarquias e identidades regionais, para expressão de suas noções - também variáveis no tempo - de direitos de uso da terra ou dos "chãos urbanos", nas vilas e cidades coloniais, o que sugere que o desenho urbano dos municípios também não foi mera imposição dos poderes públicos. ${ }^{6}$

\footnotetext{
${ }^{4}$ Disponível em: http://www.um.es/redcolumnaria/index.php?option=com_contentEvview=article $\&$ id=6\&lang=en. Acesso em: 03/08/ 2016.

5 DAVIDSON, David Michel. Rivers and empire: the madeira route and the incorporation of the Brazilian far west, 1737-1808. Dissertação em História, História da América Latina, Yale University, 1970.

${ }^{6}$ SILVA, Francisco Carlos Teixeira da. Conflito de terras numa fronteira antiga: sertão do São Francisco no século XIX. Tempo n. 7. Rio de Janeiro: UFF, 1999, p. 9-28. Disponível em: http:// www.historia.uff.br/tempo/artigos_dossie/artg7-1.pdf. Acesso em: 03/08/2016; MOURA, Denise A. Soares de. Disputas por chãos de terra: expansão mercantil e seu impacto sobre a estrutura fundiária da cidade de São Paulo. Revista de História, n. 163. São Paulo: FFLCH, USP, jul/dez 2010,
} 
A autora conclui que o processo de definição de fronteiras na península Ibérica foi menos "nacionalizado" na Europa do que na América. Especialmente para o caso ibérico mostrou como a condição fronteiriça foi uma característica predominante das autopercepções e autodefinições sociais. Neste sentido, os indivíduos foram mais próximos de seus vizinhos regionais do que de uma estrutura política como o Estado, muitas vezes com suas instituições e agentes situados geograficamente - para não dizer também do ponto de vista das aspirações e ideias - tão distantes das populações residentes nos municípios.

Mas conforme demonstram textos de representações escritos pelas câmaras, esta situação foi muito semelhante às ocorridas em todas as partes da América portuguesa, nas quais também são observadas autodefinições que evocam o local (o ter nascido na cidade ou vila, a condição de fronteiriço, de ser republicado de câmara situada em tal ou qual vila). Neste caso, também na América portuguesa a definição de suas fronteiras foi tão pouco "nacionalizada" como na península.

Para finalizar pode-se dizer que o estilo analítico narrativo da autora em alguns momentos soa imperativo, especialmente quando quer enfatizar a ação dos múltiplos agentes sociais e sua argumentação na defesa dos direitos de posse, em detrimento dos tratados, tidos como "futilidades jurídicas" (p. 12) ou concluindo por sua "completa incapacidade" de solucionar as questões de fronteira e posse.

Entretanto, não podem ser minimizadas as forças de influência das novas tendências político-ideológicas anunciadas desde os acordos de Westfália (1648), que levaram à modernização das relações internacionais e valorização da soberania dos estados baseada no direito natural. Neste sentido, mais salutar seria ver os tratados como uma das vozes na tribuna da formação territorial ibérica, lembrando ainda que todos os agentes sociais, desde o índio ao criador de gado mais abastado, fizeram uso das instituições do Estado e dos papéis públicos para expressarem suas concepções de direito.

O trabalho de Herzog reveste-se de importância acadêmica e social. Para os historiadores profissionais apresenta rigor, coerência na aplicação de uma perspectiva analítico-metodológica. É profunda na pesquisa empírica e inova ao falar de formação territorial não do Brasil, mas de Portugal na península e na América. Para os estudantes de graduação em História esta

p. 53-80. Disponível em: http://www.revistas.usp.br/revhistoria/article/viewFile/19169/21232. Acesso em: 03/08/ 2016. 
é uma rica e provocante maneira de pensar a história do Brasil na época moderna e que contribui para a formação de percepções cada vez menos regionalizadas.

Do ponto de vista social, este trabalho traz à tona questões da história da América do Sul que ainda assombram, como a do acesso dos segmentos sociais menos privilegiados a terra, historicamente marcado por conflitos e violências.

\section{Referêrencias bibliográficas}

ABREU, C. A. Caminhos antigos e povoamento do Brasil. Rio de Janeiro: Civilização Brasileira, 1975.

CORTESÃO, Jaime. Alexandre de Gusmão e o Tratado de Madri. São Paulo: Funag, 2006. 2 vol.

DAVIDSON, David Michel. Rivers and empire: the madeira route and the incorporation of the Brazilian far west, 1737-1808. Dissertação em História, História da América Latina, Yale University, 1970.

HOLANDA, Sérgio Buarque de. Monções. $3^{a}$ edição. São Paulo: Ed. Brasiliense, 1990.

MONTEIRO, John. Negros da terra: índios e bandeirantes nas origens de São Paulo. São Paulo: Companhia das Letras, 1995.

MOURA, Denise A. Soares de. An expanding mercantile circuit in the South Atlantic in the late colonial period (1796-1821). E-Journal Portuguese History, vol. 13, n. 1. Brown: Brown University, 2015, p. 68-88. Disponível em: https://www. brown.edu/Departments/Portuguese_Brazilian_Studies/ejph/html/issue25/ pdf/v13n1a03.pdf. Acesso em: 17/08/2016.

Disputas por chãos de terra: expansão mercantil e seu impacto sobre a estrutura fundiária da cidade de São Paulo. Revista de História, n. 163. São Paulo: FFLCH, USP, jul/dez 2010, p. 53-80. Disponível em: http://www.revistas.usp.br/ revhistoria/article/viewFile/19169/21232. Acesso em: 03/08/2016.

PIMENTA, João Paulo. A independência do Brasil e a experiência hispano americana (18081822). São Paulo: Hucitec, 2015.

PRADO, Fabrício. In the shadows of empires: trans-imperial networks and colonial identity in Bourboun Rio de la Plata (c. 1750-c. 1813). Dissertação em História colonial, História da América Latina, Emory Universtiy, 2009.

SILVA, Francisco Carlos Teixeira da. Conflito de terras numa fronteira antiga: sertão do São Francisco no século XIX. Tempo n. 7. Rio de Janeiro: UFF, 1999, p. 9-28. Disponível em: http://www.historia.uff.br/tempo/artigos_dossie/artg7-1.pdf. Acesso em: 03/08/2016.

Recebido: 18/08/2016 - Aprovado: 31/10/2016 